\title{
Laser ablation of thin films of molybdenum for the fabrication of contact masks elements of diffractive optics with high resolution
}

\author{
Poletaev S.D. \\ Image Processing Systems Institute, Russian Academy of Sciences, \\ Samara State Aerospace University
}

\begin{abstract}
Considered the task of reducing the thickness of the contact lines of the pattern masks used in the formation of the microrelief of diffractive optical elements (DOE) and produced by laser ablation of thin films of refractory metals. For contact mask of DOEs on molybdenum films with thickness of $40 \mathrm{~nm}$ using a laser ablation patterns recorded with elements of the picture width 0.25 $0.3 \mu \mathrm{m}$. This is approximately 3 times smaller than the characteristic dimensions, obtained by thermochemical recording chromium films of the same thickness in the standard process. Reactive ion etching in an inductively coupled plasma through a mask was formed micro-relief height up to $300 \mathrm{~nm}$ in a quartz substrate. We have shown promising applications of thin films of molybdenum as a metallic mask in the formation of microrelief of DOEs.
\end{abstract}

Keywords: diffractive microrelief, metallic mask, laser ablation, thermochemical recording, film molybdenum, reactive ion etching

Citation: Poletaev S.D. Laser ablation of thin films of molybdenum for the fabrication of contact masks elements of diffractive optics with high resolution. Proceedings of Information Technology and Nanotechnology (ITNT-2015), CEUR Workshop Proceedings, 2015; 1490: 82-89. DOI: 10.18287/1613-00732015-1490-82-89

\section{Introduction}

Thermochemical laser writing [1,2], the contact masks plays a decisive role for a wide range of [3-9] The methods of forming the microrelief diffractive optical elements. Currently, the widely used form metalized microrelief mask thin films of metals [1-2, 5], in which during exposure to laser radiation is focused thermochemical conversion of the surface layer of the working material. The starting material is widely used chromium $[1-2,5]$. The sequence of formation of micro-relief in a quartz substrate, in this case, following [5, 7]:

- Chromium plating film of a given thickness on a substrate;

- The formation of topological pattern of the future impact of the laser element in the film; 
- The creation of metallic liquid etching mask film of chromium areas not exposed to laser radiation;

- Plasma etching the substrate through the resulting metallic mask (the formation of microrelief in the substrate).

The disadvantage of this technology is pretty low resolution. Standard achievable feature size structures in this case - the order of the wavelength, i.e. about $0.8 \mu \mathrm{m}$ [10]. In this regard, the actual task is the development of technological methods for creating elements with high spatial resolution.

On the basis of the above-described process sequence, for example, in [11], there has been an element size of $0.5 \mu \mathrm{m}$ on the structure of the chromium films $50 \mathrm{~nm}$ thick inflicted thermal vacuum process substrates of optical glass.

Patent [12] describes how to increase the resolution of the method of laser thermochemical oxidation film of titanium thickness of $3-60 \mathrm{~nm}$, deposited on the glass substrate.

A characteristic feature of the studies described in [1-11], is that the resistance to the subsequent chemical resistance increases for portions of film exposed to the laser radiation. In contrast to [1-11], we propose an approach based on evaporation (ablation) portions of the film exposed to laser radiation.

The purpose of this paper is the experimental investigation of the possibility of further increasing the spatial resolution diffraction microrelief formed by using the contact masks using laser recording. It is proposed to achieve this total rejection of liquid chemical processes of lithography through the use of new materials and other physical effects of producing binary microstructures.

\section{Problem statement and proposed approach}

In [13] have demonstrated the possibility of ablation of molybdenum films picosecond laser beam with a wavelength of $1064 \mathrm{~nm}$, deposited on a sublayer of silicon nitride thickness of about $140 \mathrm{~nm}$. The grounds were glass substrate of a thickness of $3 \mathrm{~mm}$. Ablation of the films of molybdenum with a thickness of about 0.5 $\mu \mathrm{m}$ was carried out by laser beam with a maximum energy flux density of 260 $\mathrm{W} / \mathrm{cm}^{2}$, and it was suggested that the molybdenum is removed from the substrate surface without chemical transformations. In our case, a contact mask on the basis of thin films of molybdenum was used for forming a diffraction microrelief in the following sequence of operations:

- sputtering thin films of molybdenum on a substrate;

- the formation of metal mask element, the influence of laser radiation on the film of molybdenum;

- reactive-ion etching in inductively coupled plasma substrate through a metallic mask (formation of microrelief in the substrate).

The microrelief formed on substrates of fused quartz brand $\mathrm{KV}$ of size $50 \times 50 \mathrm{~mm}$, thickness $3 \mathrm{~mm}$ and 14 class of surface cleanliness. Film of molybdenum was deposited by magnetron sputtering method on the "Caroline D-12A" [14] a thickness 
of $40 \mathrm{~nm}$. The formation of topological drawing of patterns in the molybdenum film (metal mask) was performed on the laser writing station CLWS200 [5, 13] with the following parameters: operating wavelength of the laser radiation is $488 \mathrm{~nm}$; the power supplied to the recording head, is about $100 \mathrm{~mW}$; record structure - concentric rings with a pitch of $3 \mu \mathrm{m}$ and the outer radius of $2 \mathrm{~mm}$; the magnitude of the power for each ring was reduced from $100 \%$ to 0 from the maximum power in $0.5 \%$ increments. On the outer rings with the capacity of about 80 to $40 \mathrm{~mW}$, the laser radiation would result in a localized evaporation of thin films of molybdenum for all thickness down to the quartz substrate.

\section{Analysis of the results}

The results of the research profile of microstructur-ture formed in the molybdenum film when exposed to a laser beam of various capacities, represented in Fig. 1. Measurement of the profile of the microstructure was carried out on a scanning probe microscope (SPM) "Solver-Pro". On the profile visible area of complete removal of molybdenum (complete ablation). The boundary of the critical power at which ablation stops, well marked (the power decreases from left to right, Fig. 1a). On the edges of the formed structures have shown that the characteristic outbursts, which can be explained by the release of material during exposure to the beam.

In Fig. 2 shows the same image of microstructures, but obtained by scanning electron microscope (SEM) "Supra 25". The picture shows a clear band width 253$256 \mathrm{~nm}$ (Fig. 2a, b). On these pictures it can be seen that the edges of the grooves are damage to the film or the formation of the projecting profile, which is confirmed by the data obtained with SPM.

The width of the line of the laser beam (the portions of the substrate, free from films of molybdenum) is $220 \ldots 300 \mathrm{~nm}$ (Fig. 1b) and depends on the magnitude of power greater than that required for ablation, which is confirmed by Fig. 2 b.

For the formation of diffractive microrelief was used for reactive-ion etching of quartz substrates at the "Caroline PE-15" induction plasma excitation from the generator of radio-frequency voltage of $13.56 \mathrm{MHz}$. Working chamber cylindrical shape of the planar type. The etching was conducted in an environment hexafluoride $\mathrm{SF}_{6}$ [15]. To stabilize the discharge in the plasma mixture was added in argon [1618]. Power from the RF source is supplied to the inductor that is installed at the top inside the chamber. Etching of the sample 1 was carried out in the following mode: power inductor $-400 \mathrm{~W}$; power stage $-200 \mathrm{~W}$; the flow rate hexafluoride $\mathrm{SF}_{6}-60$ $\mathrm{cm}^{3} / \mathrm{min}$; flow rate of argon $\mathrm{Ar}-50 \mathrm{~cm}^{3} / \mathrm{min}$; the pressure of a gas is $5.0 \cdot 10^{-1} \mathrm{~Pa}$; the etching time of $10 \mathrm{~min}$.

The mode of etching of the sample 2 from the mode of etching of the sample 1 differs only in the time of etching, is accounted to him for $15 \mathrm{~min}$.

After reactive-ion etching of the substrate remnants of the mask was removed. 

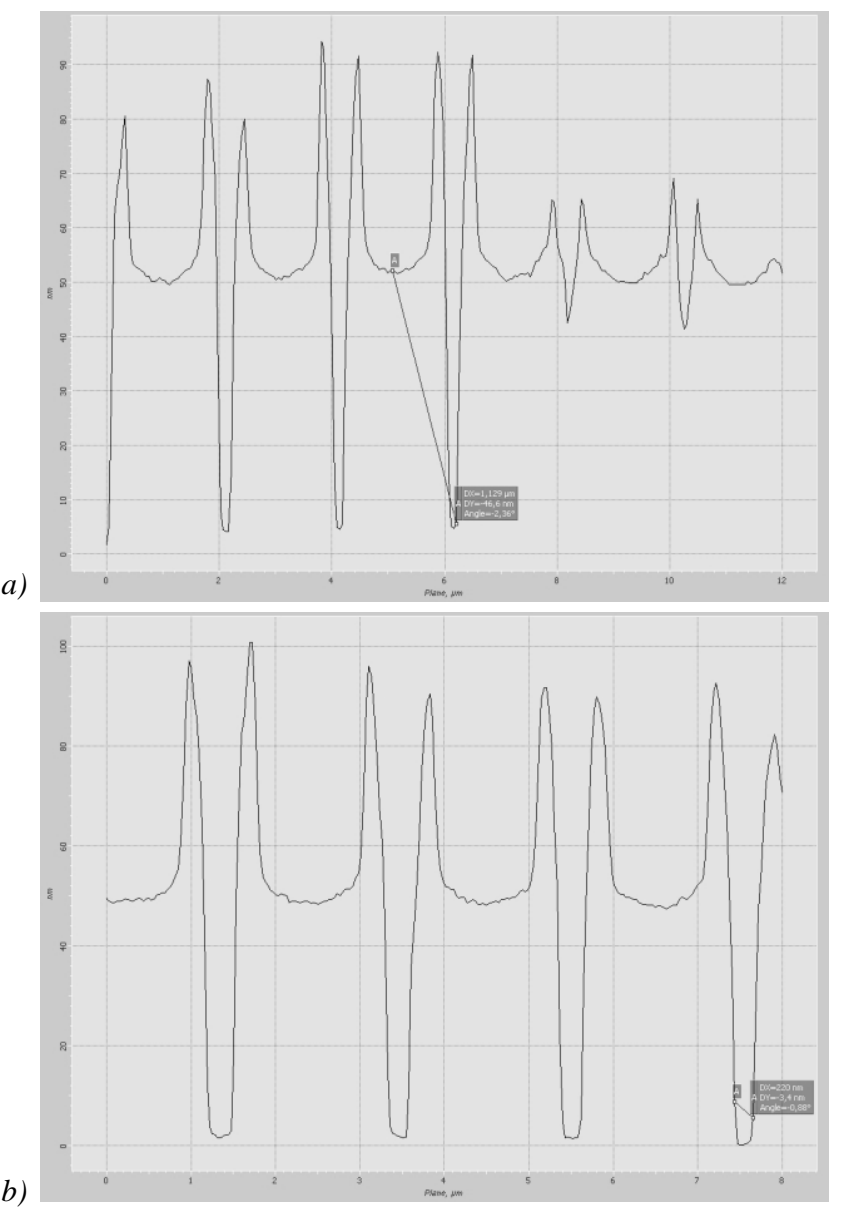

Fig. 1. - SPM results profile molybdenum film after laser writing: the border at the beginning of the burn process when the critical power (a), the recorded patterns with a line width of 220 $\mathrm{nm}(\mathrm{b})$

The resulting SPM profile of the samples is shown in Fig. 3a, b. The images show that the quality of the surface microrelief of the sample 1 is higher than sample 2 , which is probably due to the long time of etching, resulting in the masking film of the sample 2 is completely degraded in the plasma, which led to the destruction of the surface microrelief. In addition to increasing the rate of etching in these areas can be explained by changes in the chemical composition of the masking layer during laser recording, the more the height of the mask at the edges of the grooves is higher than in other areas. On the submitted drawings the width of the lines for samples 1 and $2-$ 294 and $353 \mathrm{~nm}$, respectively. 
a)

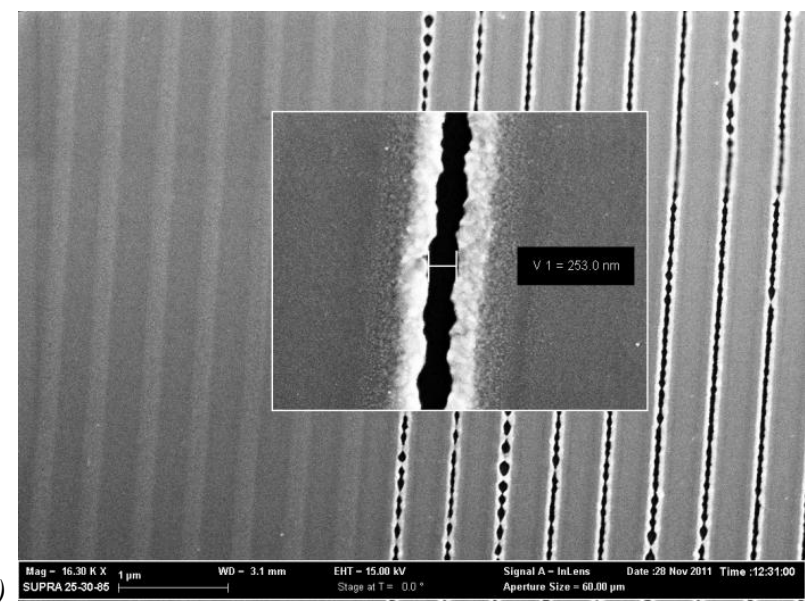

b)

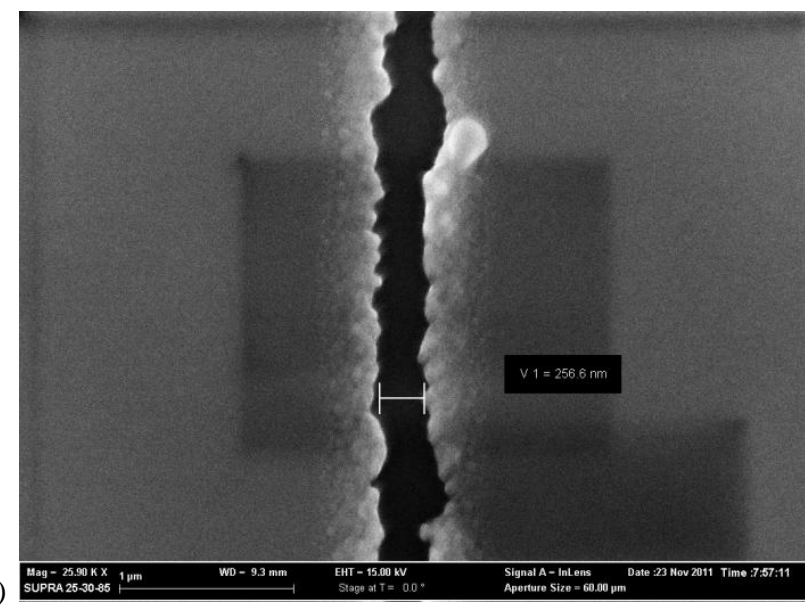

Fig. 2. - SEM image of the sample after laser writing: the border at the beginning of the burn process when reaching the critical power (a), the enlarged part of image (b)

\section{Conclusion}

In our experiments, the possibility of creating optical structures of submicron resolution, including with elements smaller than the diffraction limit $(0.25 \mu \mathrm{m})$, based on the dry etching of quartz using a contact mask obtained by the method of laser ablation of molybdenum film. Reduction of the characteristic dimensions of the diffractive microrelief [19-22] to create a DOE with a smaller focal lengths, with a larger aperture, or DOE, is designed to lower the working wavelength. Of course, the proposed improvements are not suitable for everyone [23-25] technological approaches, but can be effectively used for a wide range [3-11] methods for forming diffractive microrelief. Further research is planned and on the way of formation and 
use of thinner films ( $25 \mathrm{~nm}$ or less), which should lead to a further increase in the resolution of laser writing.

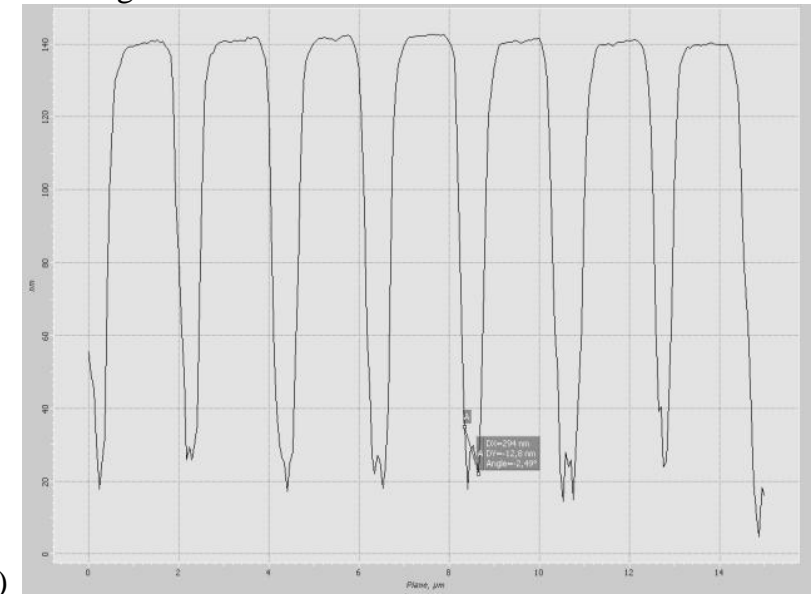

a)

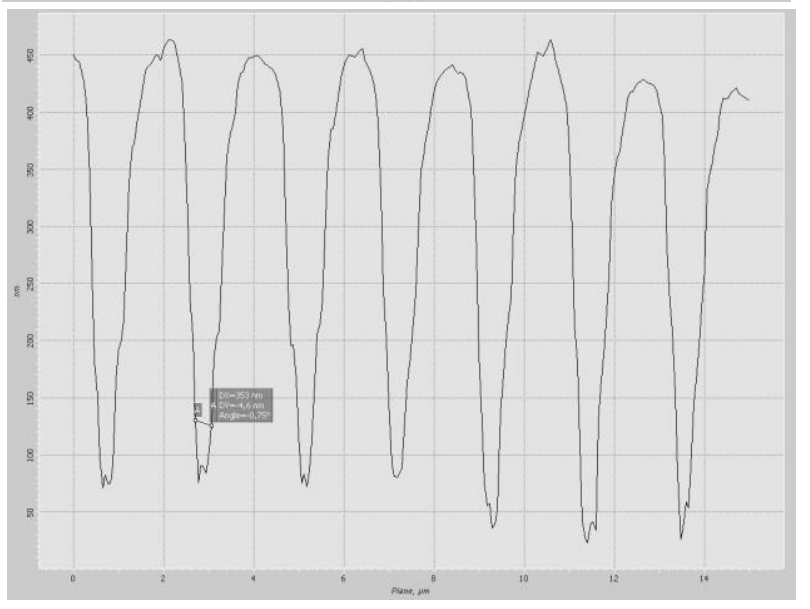

Fig. 3. - SPM microrelief formed by etching in inductively coupled plasmas: profile of sample 1 (a) profile of sample 2 (b); the line width of $294 \mathrm{~nm}$ and $353 \mathrm{~nm}$, respectively

\section{Acknowledgements}

The work is executed at financial support of the Ministry of education and science of the Russian Federation, the grant of the President of the Russian Federation for support of leading scientific schools NSH-4128.2012.9, grant RFBR No. 14-0700177a. 


\section{References}

1. Veiko VP, Korol'kov VI, Poleshchuk AG, Sametov AR, Shakhno EA, Yarchuk MV. Study of the spatial resolution of laser thermochemical technology for recording diffraction microstructures. Quantum Electronics, 2011; 41(7): 631-636.

2. Veiko VP, Sinev DA, Shakhno EA, Poleshchuk AG, Sametov AR, Sedukhin AG. Researching the features of multibeam laser thermochemical recording of diffractive microstructures. Computer Optics, 2012; 36(4): 562-571. [in Russian]

3. Volkov AV, Kazanskiy NL, Rybakov OYe. The study of plasma etching technology for creation of multi-level diffractive optical elements. Computer Optics, 1998; 18: 127-130. [in Russian]

4. Volkov AV, Kazanskiy NL, Rybakov OYe. Development of technology for creation of diffractive optical elements with submicron dimensions of the relief in the silicon wafer. Computer Optics, 1998; 18: 130-133. [in Russian]

5. Poleshchuk AG, Churin EG, Koronkevich VP, Korolkov VP, Kharissov AA, Cherkashin VV, Kiryanov VP, Kiryanov AV, Kokarev SA, Verhoglyad AG. Polar coordinate laser pattern generator for fabrication of diffractive optical elements with arbitrary structure. Applied Optics, 1999; 38(8): 1295-1301.

6. Kazanskii NL, Kolpakov VA, Kolpakov AI. Anisotropic etching of $\mathrm{SiO}_{2}$ in high-voltage gas-discharge plasmas. Russian Microelectronics, 2004; 33(3): 169-182.

7. Kazanskiy NL. A research complex for solving computer optics problems. Computer Optics, 2006; 29: 58-77. [in Russian]

8. Pavelyev VS, Borodin SA, Kazanskiy NL, Kostyuk GF, Volkov AV. Formation of diffractive microrelief on diamond film surface. Optics \& Laser Technology, 2007; 39(6): 1234-1238.

9. Bezus EA, Doskolovich LL, Kazanskiy NL. Evanescent-wave interferometric nanoscale photolithography using guided-mode resonant gratings. Microelectronic Engineering, 2011; 88(2): 170-174.

10. Kazanskiy NL. Research and technological center of diffraction optics. Bulletin of Samara Scientific Center of the Russian Academy of Sciences, 2011; 13(4-1): 54-62. [in Russian]

11. Agafonov AN, Moiseyev OYu, Korlyukov AA. The analysis of dependence of resolution of technology of local thermochemical oxidation from parameters of structure of a photosensitive film of chrome. Computer Optics, 2010; 34(1): 101-108. [in Russian]

12. Jörgens R, Gorbunov A, Pompe W. Verfahren und Anordnung zur Erzeugung von Strukturen im Submikrometerbereich. Patent DE19544295A1 - 05.06.1997. G02B 5/18, 21/00.

13. Heise G, Englmaier M, Hellwig C, Kuznicki T, Sarrach S, Heinz P. Huber Laser ablation of thin molybdenum films on transparent substrates at low fluences. Applied Physics A: Materials Science \& Processing, 2011; 102(1): 173-178.

14. Kazanskiy NL. Research and Education Center of Diffractive Optics. Proceedings of SPIE, 2012; 8410: 84100R. doi: 10.1117/12.923233.

15. Zeze DA, Forrest RD, Carey JD, Cox DC, Robertson ID, Weiss BL, Silva SRP. Reactive ion etching of quartz and Pyrex for microelectronic application. Journal of Applied Physics, 2002; 92(7): 3624-3629.

16. Xuming W, Changhe Z, Peng X, Enven D, Huayi R, Liren L. Etching quartz with inductively coupled plasma etching equipment. Proceedings of SPIE, 2003; 5183: 192198. 
17. Volkov AV, Kazanskiy NL, Kostyuk GF, Pavelyev VS. Dry Etching of Polycrystalline Diamond Films. Optical Memory And Neural Networks (Information Optics), 2002; 11(2): 135-137.

18. Nesterenko DV, Poletaev SD, Moiseev OYu, Yakunenkova DM, Volkov AV, Skidanov RV. Creating a curved diffraction gratings for ultraviolet. Bulletin of Samara Scientific Center of the Russian Academy of Sciences, 2011; 13(4): 66-71. [in Russian]

19. Golub MA, Kazanskii NL, Sisakyan IN, Soifer VA. Computational experiment with plane optical elements. Optoelectronics, Instrumentation and Data Processing, 1988; 1: 7889.

20. Kazanskiy NL. The study of the diffraction characteristics of focusators into the ring by computational experiment. Computer Optics, 1992; 10-11: 128-144. [in Russian]

21. Kazanskiy NL, Soifer VA. Diffraction investigation of geometric-optical focusators into segment. Optik, 1994; 96(4): 158-162.

22. Doskolovich LL, Kazanskiy NL, Soifer VA. Comparative analysis of different focusators focusing into segment. Optics and Laser Technology, 1995; 27(4): 207-213.

23. Kazanskiy NL, Murzin SP, Osetrov YeL, Tregub VI. Synthesis of nanoporous structures in metallic materials under laser action. Optics and Lasers in Engineering, 2011; 49(11): 1264-1267. doi: 10.1016/j.optlaseng.2011.07.001.

24. Volkov AV, Kazanskiy NL, Moiseev OYu, Soifer VA. A Method for the Diffractive Microrelief Formation Using the Layered Photoresist Growth. Optics and Lasers in Engineering, 1998; 29(4-5): 281-288.

25. Abul'khanov SR, Kazanskii NL, Doskolovich LL, Kazakova OY. Manufacture of diffractive optical elements by cutting on numerically controlled machine tools. Russian Engineering Research, 2011; 31(12): 1268-1272. 